\title{
Supply Chain Improvement in Construction Industry
}

\author{
Georgios A. Papadopoulos*, Nadia Zamer, Sotiris P. Gayialis, Ilias P. Tatsiopoulos \\ Sector of Industrial Management and Operational Research, School of Mechanical Engineering, \\ National Technical University of Athens, Greece
}

Copyright $(02016$ by authors, all rights reserved. Authors agree that this article remains permanently open access under the terms of the Creative Commons Attribution License 4.0 International License.

\begin{abstract}
In a very competitive and complex industry like the construction industry with demands for the delivery of top quality projects at very competitive prices, a significant need for an effective management of the construction supply chain has arose. Construction Supply Chain Management (CSCM) is a very promising approach to successfully achieve integration between the several disciplines of the chain (i.e. internal and external suppliers, designers, vendors, contractors, subcontractors and internal and external clients). Big international construction companies have carried out extensive research and developed computer based platforms to experiment the recent Supply Chain Management (SCM) concepts. Even though SCM in the manufacturing industry has been widely researched and developed, the application of the same concepts to the construction industry shows problems in construction supply chains are extensively present and persistent. Analysis of these problems has shown that a major part of them originate at the interfaces between the various disciplines or functions and the complex nature of the construction environment. The aim of this research study report is to provide a set of propositions for improving construction supply chain management such as benchmarking, improvement of suppliers/subcontractors performance, elimination of waste, training and information sharing between parts of the supply chain. The study includes the literature review regarding the trends of the supply chain management in construction industry, the specific characteristics and problems in coordinating construction supply chain and finally it suggests improvements in supply and demand management based on integration, collaboration, information sharing and trust.
\end{abstract}

Keywords Supply Chain Management, Construction Industry, Improvement, Literature Review

\section{Introduction}

Supply Chain Management (SCM) has been widely analyzed in the academic literature related to operations management. Most of research is focused on quantitative and qualitative approaches. Quantitative modeling is applied to inventory management, demand forecasting and routing optimization. These studies are highly related to data analysis from case studies in manufacturing processes. Qualitative, managerial or soft aspects of SCM are usually related to the definition of frameworks, which are applied within industry and after that are validated through empirical research. Such frameworks are usually applied in performance measurement, strategic planning and governance in SCM.

Construction management has unique characteristics related to its nature such as an intermittent flow and non-repeated projects. Quantitative and modelling studies are not easily applied within construction environment due to its complexity for two main reasons:

- non-repeated projects take along difficulties to production standardization and modularization, not contributing to obtain gains of scale in production systems.

- construction management presents a lack of integration between designers, vendors, main contractors, subcontractors, suppliers, site team and finally the client. Integrated efforts are key aspects to improve performance, not only to deliver better projects on/or before completion time to the clients, but also to reduce waste and to promote cost reduction throughout the supply chain (SC).

Advanced and newly developed practices of supply chain management in industrial engineering can be directed implemented or adapted to the construction industry.

The purpose of this paper is to propose some methods for improving construction supply chain management. Such proposition is based on a literature review of SCM considering mainstream journals of construction/industrial engineering and the proceedings of the last conferences of the International Croup of Lean Construction. This paper has four further sections. The second section provides a definition of supply chain and analyzes the benefits of the application of supply chain management. The third section focuses on supply chain in construction/industrial sector analyzing the special characteristics, the problems and the 
areas of focus of the supply chain in the construction sector compared to the ones in the manufacturing sector. The fourth section presents a discussion of improvement in the construction supply chain management. Finally, a concluding section includes research limitations and suggests topics for further research.

\section{Supply Chain Definition and Supply Change Management Benefits}

In accordance with the academic literature, supply chain is a network of:

- Autonomous or semi-autonomous business entities collectively responsible for procurement, manufacturing, and distribution activities associated with one or more families of related products [Teigen, (1997), Swaminathan et al, (1996)].

- Facilities that procure raw materials, transform them into intermediate goods and then final products, and deliver the products to customers through a distribution system [Lee et al., (1995)].

- Facilities and distribution options that performs the functions of procurement of materials, transformation of these materials into intermediate and finished products, and the distribution of these finished products to customers [Ganeshan et al., (1995)].

It is obvious that all these definitions are in a fully agreement.

In general supply chain is a network of organizations involved, from the supplier of the supplier until the client of the client, on the different processes and activities that produce value in the form of products and services for the final client. Its major components are the suppliers' network, the transformation unit and the clients' network. The effective management of the supply chain is necessary for successful competition in today's global markets.

SCM is a philosophy that describes how organizations should manage their supply chains to achieve strategic advantages. Its goal is to synchronize the client requirements with the materials and information flows along the supply chain, until reaching a balance between the client satisfaction and the cost. It refers then to the coordination of the activities of all that participate in the supply chain, to knowing the production requirements with the purpose of satisfying the client, to delivering of products of higher value and to reducing the costs of the organization that apply these principles.

The application of the SCM, mainly in the manufacturing industry, has been successful and has achieved the expected benefits [Roth and Martin, (2000), Proverbs and Holt, (2000), Landry, (1998), Christopher, (1992)]. Some of these benefits are: reduced real costs, with margins maintenance, incentive to remove waste from the process, competitive advantages, greater certainty of out-turn costs, delivery of better underlying value to the client, on time delivery, productivity improvement, value creation, more repeat business with key clients, greater confidence in longer-term planning and better relationships between parties. The benefits for end-users and project clients include a more responsive industry delivering facilities that better meet user needs, delivered to time and cost with minimum defects. This in turn creates higher customer satisfaction levels and an improved reputation for the industry.

This can be achieved by four proposed critical factors that were determined after an analysis of the SCM literature: information integration of the whole company, operational coordination and collaboration, focus on the client and development of general strategies in the whole chain [Ross, (1998), La Londe, (1998), Lee and Whang, (2001), Roth and Martin, (2000)].

\section{Supply Chain in Construction}

\subsection{Characteristics of Construction Supply Chains}

Although the construction process is different than the manufacture process, SCM can be useful and effective in construction [O'Brien, (1999)]. SCM is a very promising approach to successfully achieve integration between internal and external suppliers, designers, vendors, contractors, subcontractors and internal and external clients.

For analysing the application of Supply Chain Management In Construction (SCMC) it is necessary to specify a construction "product", compared to a manufactured one, since SC cannot be applied in the same way to the two domains by presenting the main characteristics of construction in terms of supply chain. Some critical differences between supply chain in manufacture and supply chain in construction are:

- The construction product is for a single client most of the times.

- The product changes for each project.

- The place, equipment and methods of production change for each project.

- Construction personnel have a high rotation index during the construction time and between projects.

- Not all the parts and materials can be stored at site.

In terms of structure and function, for Vrijhoef et al., the construction supply chain is characterised by the following elements [Vrijhoef et al., (2000)]:

- It is a converging supply chain directing all materials to the construction site where the object is assembled from incoming materials. The "construction factory" is set up around the single product, in contrast to manufacturing systems where multiple products pass through the factory, and are distributed to many customers.

- It is, apart from rare exceptions, a temporary supply chain producing one-off construction projects 
through repeated reconfiguration of project organisations. As a result, the construction supply chain is typified by instability, fragmentation, and especially by the separation between the design and the construction of the built object.

- It is a typical make-to-order supply chain, with every project creating a new product or prototype. There is little repetition, again with minor exceptions. The process can be very similar, however, for projects of a particular kind.

\subsection{Problems of the Construction Supply Chains}

Figure 1 represents a sample of a system of multiple supplier - client relationships that are needed to complete a construction project, the interfaces between the several parties of the chain and the various problems that affect the construction supply chain as these have been reported by several authors [Vrijhoef and Koskela, (1999), Vrijhoef, (1998), Hong-Minh et al., (2000); Akintoye et al., (2000), O’Brien, (1999), Ofori, (2000), Vrijhoef et al., (2001)].Most of these problems are not generated in the conversion process but in the different interfaces of different parties or functions, that exist within the supply chain. Some of the general problems are as follows:

- $\quad$ Client / Feed, Design Interface: difficulties in finding out client's wishes, changes of client's wishes, long procedures to discuss changes, interfaces with other relevant parties throughout feed and design period.

- Feed Design / Engineering Interface: incorrect documents, design changes, extended time for design changes and approval, wrong calculations, designs not in accordance with the well-known construction methods, no constructability.

- Engineering / Procurement, Vendors Interface: inaccurate data, engineering drawings not fit for use.

- $\quad$ Engineering / Site Interface: engineering team not present on site for the field engineering.

- Engineering / Commissioning, Procurement / Commissioning, Main Contractor / Commissioning, Subcontractors, Suppliers / Commissioning Interfaces: difficult interfaces between various disciplines, problematic completion due to quality problems.

- Project Completion / Commissioning Interface: problematic completion due to quality or safety problems, problems with local communities.

- Procurement, Vendors / Suppliers Interface and Procurement, Vendors / Subcontractors: inaccurate data, technical specifications not met, other changes, lack of coordination, collaboration and commitment between suppliers, poor quality of materials and components.

- Procurement / Logistics Interface: not proper logistic studies, not effective logistics routes, not obtained permits \& licenses needed, customs clearance delays.
- Logistics / Site Interface: large shipments, not proper packing, bad weather or political conditions, long storage period.

- Main Contractor / Subcontractors Interface: deliveries not according to planning late deliveries of permanent materials, wrong and defective deliveries, large shipments, long storage period, interfaces with several subcontractors and suppliers, poor training of contractor's suppliers, subcontractors and workers, inadequate management within the supply chain, mainly poor.

- Suppliers and Subcontractors / Site Interface: deliveries not in conformance with planning, wrong and defective deliveries, long storage period, subcontracted work not delivered according to main design, contract and planning, low productivity of several subcontractors, poor training of workers, deficient communication and information transfer.

- $\quad$ Site / Completion of Project and Project Completion / Commissioning Interfaces: problematic completion due to quality or safety problems, problems with local communities.

- Commissioning / Operation Interface: unresolved quality and technical problems, delayed operational time due to late completion.

The current practice of supply chain management suggests controlling the supply chain as an integrated value-generating flow, rather than only as a series of individual activities. For this generic model of the problems in the construction process, the term "supply chain" refers to the stages through which construction materials factually proceed before having become a permanent part of the project. The term covers thus both permanent supply chains, that exists independent of any particular project, and temporary supply chains, configured for a particular project.

\subsection{Areas of Focus and Roles of Supply Chain Management in Construction}

Using the lessons learnt from SCM in manufacturing as a starting point, there is a definition of the four roles of SCM in the construction industry. There is a discussion of the limitations of the four roles of SCM in the construction industry, and a presentation of recommendations for SCM in construction.

The characteristics discussed above have an impact on the management of supply chains. Four major roles of SCM in construction can be recognised, dependent on whether the focus is on the supply chain, the construction site, or both. They are:

- The focus may be on the impacts of the supply chain on site activities. The goal is to reduce costs and duration of site activities. In this case, the primary consideration is to ensure dependable material and labour flows to the site to avoid disruption to the workflow. This may be achieved by simply focusing 
on the relationship between the site and direct suppliers. The contractor, whose main interest is in site activities, is in the best position to adopt this focus.

- The focus may be on the supply chain itself, with the goal of reducing costs, especially those relating to logistics, lead-time and inventory. Material and component suppliers may also adopt this focus.

- The focus may be on transferring activities from the site to earlier stages of the supply chain. This rationale may simply be to avoid the basically inferior conditions on site, or to achieve wider concurrency between activities, which is not possible with site construction with its many technical dependencies. The goal is again to reduce the total costs and duration. Suppliers or contractors may initiate this focus.

- $\quad$ The focus may be on the integrated management and improvement of the supply chain and the site production. Thus, site production is subsumed into SCM. Clients, suppliers or contractors may initiate this focus.
It should be noted that the roles as identified above are not mutually exclusive, but are often used jointly. The focus here is on the supply chain of a main contractor. However, there is a fifth important role that lies in the management of the construction supply chain by facility, or real estate owners.

They may well drive the management and development of the construction supply chain on which they are reliant for the continuation of their business, for instance when they exploit a number of facilities that need frequent new development and refurbishment.

Given this configuration of the construction supply chain, a construction company has as many supply chains as it has construction projects, because for each project the client's needs and the project's characteristics might be different. As shown in Figure 1, the supply chain in construction represents a system of multiple supplier - client relationships that are needed to complete the project. Besides, every supply activity ends when the project is handed over to the client. Another particularity is the number of clients. Compared to the manufacturing supply chain, the number of clients in construction is very limited, generally one.

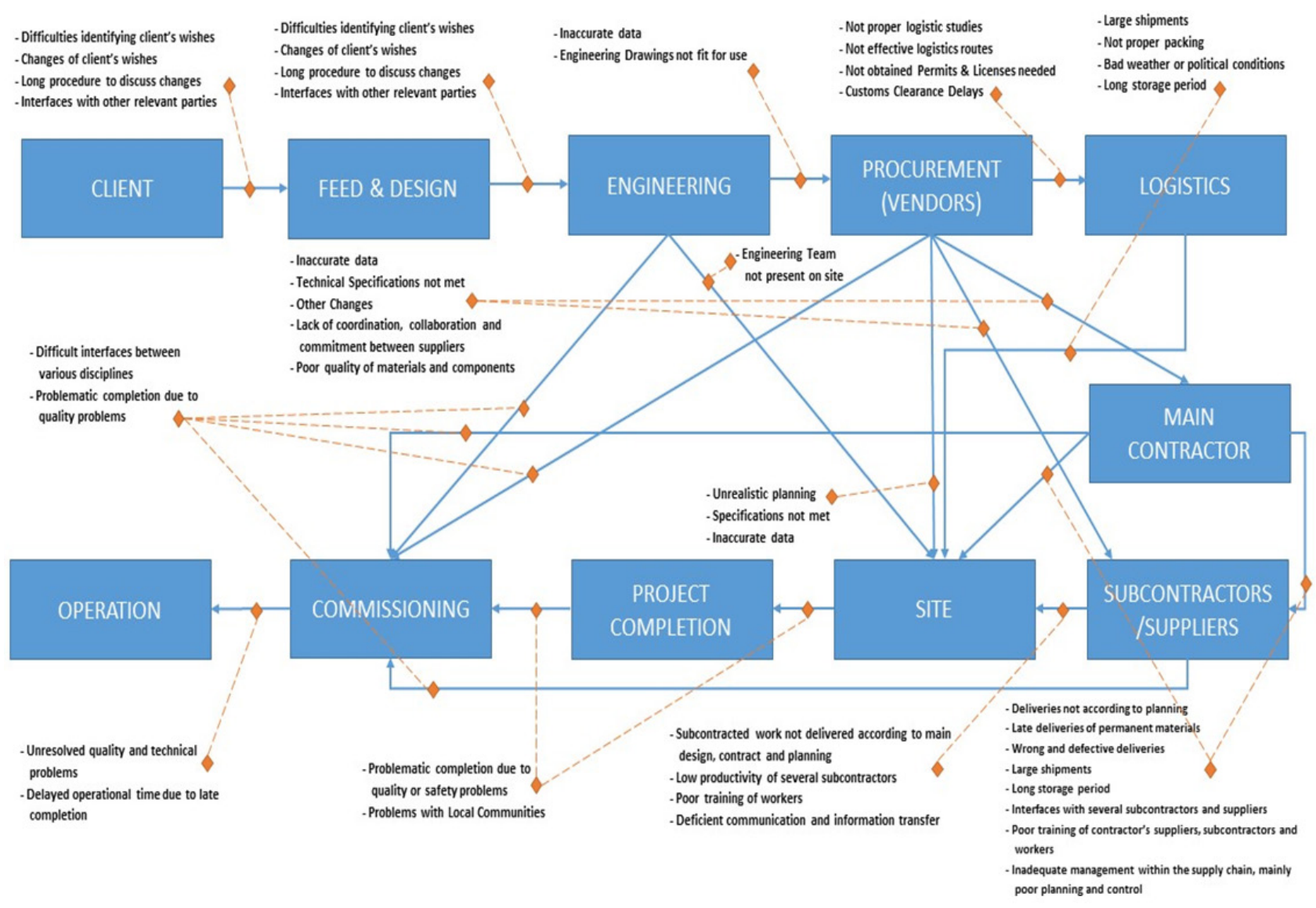

Figure 1. Sample of a system of multiple supplier - client relationships 


\section{Improvement in Construction Supply Chain}

\subsection{Current Research Status}

There is a lack of academic studies in terms of improvement of supply chain as a process. One of the first studies related to SCM metrics was presented by [Beamon, (1999)]. A framework that links supply chain processes and its levels was later presented by [Gunasekaran et al., (2004)]. The study brought a contribution to knowledge by relating the formal processes of supply chain, namely plan, source, make/assemble, and deliver. Such processes are then evaluated under different time perspectives, from the operational, tactical and strategic level. Another study was developed by [Vachon et al., (2009)] by revisiting the topic of competitive priorities and the deployment of metrics. The study had a positive response and was applied in the industry. A framework for measuring logistics performance in the wine industry by applying a multi-criteria method based on competitive priorities was developed by [Garcia et al., (2012)].

However, the last years, the research regarding supply chain management is very active in the construction sector. Big international construction companies (vendors, suppliers, contractors, subcontractors, etc.) have developed a very deep research and developed computer based platforms experimenting the recent SCM concepts.

The application of performance measures in supply chain has demonstrated to be a really important topic of research. The development of frameworks that provide efficient and accurate measures is not only necessary but urgent. In order to avoid implications, these frameworks should be developed under an easy-to-implement and handling perspective. For that reason the best scenario would be the development of these frameworks not only by academics but also by practitioners that will be capable of implementing them within the industry environment. Performance measurement is the key issue of decision making, especially in a dynamic atmosphere involving different suppliers, numerous customers and many conflicting requirements. Also, performance measurement is a means to establish a continuous improvement strategy.

\subsection{Methods to Improve Construction Supply Chain Management}

Taking into consideration the lack of academic studies and the increased show of interest of big construction companies to improve the construction supply chain and to succeed an effective management of the construction chain, the development of a set of propositions for improving construction supply chain management would be helpful to develop structured approaches between the construction companies and their contractors, resulting in better results for the entire supply chain.
The proposition of these managerial practices also promotes a different discussion in terms of supply chain improvement in construction. First, these practices are focused on the strategic level, in which there is a lack of research. Second, the shift from an operational to a strategic view places supply chain improvement as a corporate matter that should be taken in consideration for strategic planning purposes.

The subsections below is an attempt to propose a se $t$ of managerial practices in order to improve construction supply chain management.

\subsubsection{Suppliers' and Subcontractors' Development}

The interfaces between construction companies and their contractors is continuous through the whole duration of a project. In this sense, the performance delivered by the contractors influences the overall performance of the project. Major companies related to manufacturing have developed initiatives concerned about suppliers' development.

Such initiatives comprise structured programs based on training, consulting, and feedback provided to the suppliers. In general, these programs are led by the focal (major) company within the supply chain, which invest capital to support these programs in order to obtain better results in terms of cost, quality, dependability, among others, from its suppliers. After this period, the suppliers are ranked and some of them are conducted to a higher level of development in a new cycle.

\subsubsection{Performance Measurement}

Measure the performance of the processes is an ongoing challenge for companies from all sectors. Research regarding performance measurement is recent and provided frameworks that provide guidelines for managers in implementing performance measurement. Usually, the difficulties are first concentrated in defining the metrics and second in using the information provided by them for improvement.

Nevertheless, the use of performance measurement systems proves to be crucial in order to face the current market competition. The use of standardized metrics to assess the performance of suppliers and provide feedback for them is a powerful approach for supply chain management improvement. Such approach refers to the traditional view of PDCA cycle (Plan, Do, Check, Action), in which "Check" is totally related to performance measurement and give directions to correct the course of action.

\subsubsection{Benchmarking}

The development of benchmarking is still incipient in supply chain management. Benchmarking is based on best-practices exchange between companies in order to obtain improvement in their processes. Also, benchmarking can also be directed to compare the performance of metrics in order to establish goals to be reached in a determined 
period of time. In this sense, it would very helpful for the construction companies to promote benchmarking in their sector, considering the best practices for management and identifying the gap between their internal practices and the benchmarks. Nevertheless, the implementation of a benchmarking program is a complex initiative, requiring efforts to align expectations and develop trust within the entire supply chain.

\subsubsection{Knowledge Management}

In a typical supply chain, the suppliers develop knowledge not only about their products and services but also about supply chain management. Even though there are many suppliers in a single supply chain, it is rare to observe a focal (major) company that gather knowledge from its suppliers. In this sense, clearly is established an opportunity for implementing knowledge management in supply chain. The establishment of an integrated platform for knowledge sharing can deliver substantial results for supply chain improvement, especially in construction companies that are used to have internal knowledge management practices.

\subsubsection{Waste Identification and Elimination (Lessons Learnt)}

Research about waste identification and elimination is still incipient. However, the adoption of practices aiming at identifying non value added activities or processes and eliminate them can improve supply chain management. An investigation of the processes in a detailed way can produce a total redesign of their flows and lead to optimized processes. Also, at the operations level (purchasing, stocking, handling, etc.) some efforts could be done in order to identify redundant activities and eliminate them. The application of this philosophy throughout the many tiers of supply chain can deliver great results from a systemic point of view, given that the interaction between the companies is constant and their individual results influence the overall performance of supply chain.

\subsubsection{Information Technology}

The application of IT in SCM has significant benefits. The use of web-based information system in SCM will reduce interfacing barriers between the several parties on the supply chain. The information and communication technology (ICT) will improve supply chain performance, support supply chain efficiency, and enable greater supply chain integration. The several supply chain participants (i.e. Contractor, Suppliers, Subcontractors, etc.) should develop compatible IT application software and common analysis methods of the complex data.

\subsubsection{Human Resource and Training}

The importance of human factor is very important and qualified employees are required. In this sense, companies should periodically prepare an extensive and comprehensive training program to equip the best employees with proper training benefiting as a result the supply chain processes. Managerial support and employee commitment and strengthen by effective training, it will lessen the supply chain implementation barriers and will enhance supply chain performance.

\section{Conclusions}

Construction is a productive process that has various and complex interfaces between participants and many problems originated by the lack of coordination of these participants. SCM provides several principles to address this fragmentation and reduce it. Even though SCM in the manufacturing industry has been widely researched and developed, the application of these same principles to the construction industry shows waste and problems in construction supply chains are extensively present and persistent.

Some of the major benefits that construction organizations can achieve by applying SCM principles are: reduced real costs, with margins maintenance, incentive to remove waste from the process, competitive advantages, greater certainty of out-turn costs, delivery of better underlying value to the client, on time delivery, productivity improvement, value creation, more repeat business with key clients, greater confidence in longer-term planning and better relationships between parties. The benefits for end-users and project clients include a more responsive industry delivering facilities that better meet user needs, delivered to time and cost with minimum defects.

The aim of this research study report is to provide a set of propositions for improving construction supply chain management. The study is based on literature review regarding the definition of the supply chain, the benefits of supply chain management, the characteristics and problems of the supply chain in construction and finally it focuses on the improvement in construction supply chain management by suggesting practices to be studied and implemented. Such practices are well developed in industrial engineering and they are recommended to be implemented in the construction management.

As a conclusion a deep and detailed academic and practical (by companies) research of the improvement process in construction supply chain management proves to be necessary in order to orient research developments on this topic.

\section{REFERENCES}

[1] Akintoye, A., Macintosh, G., Fitzgerald, E. (2000). A survey of supply chain collaboration and management in the UK construction industry, European Journal of Purchasing and Supply Management, Special Issue.

[2] Beamon, B. (1999). "Measuring supply chain performance". 
International Journal of Operations \& Production Management, 19(3), pp.275-292.

[3] Ganeshan, R., Harrison, T. P. (1995). An Introduction to Supply Chain Management. Penn State University: $\mathrm{http}: / / \mathrm{lcm} . c s a . i i s c . e r n e t . i n / \mathrm{scm} /$ supply_chain_intro.html.

[4] Garcia, F., Marchetta, M., Camargo, M., Morel, L., Forradellas, R. (2012). "A framework for measuring logistics performance in the wine industry". International Journal of Production Economics, 135(1), pp.284-298.

[5] Gunasekaran, A., Patel, C., McGaughey, R. (2004). "A framework for supply chain performance measurement". International Journal of Production Economics, 87(3), pp.333-347.

[6] Hong-Minh, S.M., Disney, S.M., Naim, M.M. (2000). The dynamics of emergency transhipment supply chains. International Journal of Physical Distribution and Logistics Management 30 (9), 788-815.

[7] La Londe, B. (1998). Building a Supply Chain Relationship, Supply Chain Management Review.http://fisher.osu.edu/sup plychain/pdf-files/scmr.

[8] Landry, J. (1998). Supply Chain Management, Harvard Business Review, Nov - Dec.

[9] Lee, H.L., Billington, C. (1995). The Evolution of Supply-Chain-Management Models and Practice at Hewlett-Packard. Interfaces 25.

[10] Lee, H., Whang, S. (2001). E-Business and Supply Chain Integration, Stanford Global Supply Chain Management Forum, SGSCMF-W2-2001, E-business and Supply Chain Management, Stanford University. USA.

[11] O'Brien, W. (1999). Construction supply chain management: a vision for advanced coordination, costing and control, http://www.ce.berkeley.edu/ tommelein/CEMworkshop.htm.
[12] Ofori, G. (2000). Greening the construction supply chain in Singapore, European Journal of Purchasing and Supply Management, Special Issue.

[13] Proverbs, D., Holt, G.D. (2000). Reducing construction costs: European best practice supply chain implications, European Journal of Purchasing and Supply Management, Special Issue.

[14] Ross, F. (1998). Competing Through Supply Chain Management, Kluwer Academic Publishers, USA.

[15] Roth, R., Martin, J. (2000). Supply Chain Management Development Strategy. ECRU Technologies Publisher.

[16] Swaminathan, J. M., Smith, S.F., Sadeh, N. M. (1996). A Multi Agent Framework for Modeling Supply Chain Dynamics. Technical Report, The Robotics Institute, Carnegie Mellon University.

[17] Teigen R. (1997). Information flow in a supply chain management system, Diploma thesis.

[18] Vachon, S., Halley, A., Beaulieu, M. (2009). "Aligning competitive priorities in the supply chain: the role of interactions with suppliers". International Journal of Operations \& Production Management, 29(4), pp.322-340.

[19] Vrijhoef, R. (1998). Co-makership in construction: towards construction supply chain management, Graduate Thesis, Technical Research Centre of Finland, Espoo.

[20] Vrijhoef, R., Koskela, L. (1999). Roles of supply chain management in construction, 7th Conference of the International Group for Lean Construction, Berkeley, USA.

[21] Vrijhoef, R., Koskela, L. (2000). "The four roles of supply chain management in construction". European Journal of Purchasing \& Supply Management, 6(3-4), pp.169-178.

[22] Vrijhoef, R., Koskela, L., and Howell, G. (2001). "Understanding construction supply chains: an alternative interpretation." Proceedings 9th Annual Conference International Group for Lean Construction, Singapore. 